\title{
Elevating the Educational Culture for Intellectual and Socio-Economic Progress: A Case Study of Pakistan
}

Pervez Mohsin*

\begin{abstract}
This paper will attempt to explore the processes of development of educational cultures and the impact of such education on the intellectual development and socio-economic fabric. Educational cultures have been developed, have progressed and are examined within an entire social environment including interdependent socio-economic relations recognizing the impact of historical contingencies and intercultural contacts. Pakistan will be the focus of this study. The purpose of this research is an attempt to explore some progressive ways and means to improve the educational approach in Pakistan.

This paper will investigate the impact of educational systems on the development of societies that encourage and cultivate academic cultures of research and scholarship through the development of intellectual thought processes. In other words, what are the ingredients of a successful educational culture? And what steps could be taken to develop progressive educational paradigms in Pakistan at various levels? This paper will also explore the possibilities of utilization of mass media to improve the educational culture of Pakistan. As the mass media has greatly reduced the meaning of geographic distance, has increased the level, speed, and capacity of modern communication and provides incredible opportunities for highly progressive human interactions worldwide. This provides the perfect venue for the creation of a public sphere which encourages the development of an environment that promotes dedication and commitment to intellectual expansion at various levels.
\end{abstract}

Keywords: elevate educational culture, socio-economic progress

\section{Introduction}

The main purpose of this research is to explore how to elevate the educational culture in Pakistan. In other words, to find out the steps that needs to be taken to improve the educational setup so that the outcome would be progressive intellectually as well as socio-economically?

It would be imperative, in this regard, to understand not only the current educational cultural trends but also the concept of education in the classical sense. Is there any correlation between the classical and the current educational trend? How does the educational culture affect the socio-economic fabric of a society? Are these sufficient grounds for elevating the educational culture?

\footnotetext{
* Pervez Mohsin is Lecturer at National University of Computer and Emerging Sciences (FAST) Karachi, pervez.mohsin@nu.edu.pk
} 
To develop progressive educational paradigms in Pakistan at all levels some vital questions must be answered: What is the primary purpose of education? How do we define the term education? Is literacy enough for the intellectual and socio-economic progress of a society? What different kinds of educational options are available today, especially in Pakistan? How important is the role of teacher competency in the dissemination of education? And, by focusing primarily on technical curriculums, at the expense of social sciences, does a society confine itself to a narrow and limiting perception; striving to perfect the smaller pieces of the puzzle without an awareness of the overall picture?

Satisfactorily addressing the above areas of concern would clearly reveal how to elevate the educational culture in Pakistan.

\section{Development of Educational Cultures and the Impact of such Education on the Intellectual Development and Socio-Economic Fabric}

\subsection{A Historical Perspective}

Throughout the human history, as cultures began to extend their knowledge beyond the basic skills of communicating, trading, gathering food, religious practices, etc., formal education eventually followed. The body of knowledge increased exponentially, and so cultures recognized the need to preserve and pass it on to later generations.

In the pre-renaissance middle ages in the West, education and religion were deeply interrelated. The Church directly or indirectly influenced educational institutions. The curriculum for young students included the theological, philosophical, legal and ethical teachings of the Church. 'This situation is very reminiscent of the madrasahs and other religious institutions in the Islamic world attended by students from an early age.'2 (Nasr, 1993)

Actually, education in the Islamic world was more widespread than seen in the premodern West. Islamic educational institutions in the middle ages influenced the realm of higher education in the West to the degree that the entire college system from which emanated modern western universities closely related to the madrasah system originated by Muslims. Many educational practices of higher learning found in the educational institutions of Paris, Oxford and Cambridge closely resembled the practices of classical Islamic educational system which emphasized the training of both the mind and the soul.

However, as 'modernism' crept through Europe, seats of learning began to formulate ideologies and connotations critical of religious worldviews. At this point, universities began to generate ideas that separated ethics, morality and religion from socio-economic, political and educational realms. Thus began the secularization of ideologies, the parting of the mind and the soul. This compartmentalization of the branches of knowledge

\footnotetext{
${ }^{2}$ The historical concept of "madrasahs" should not be confused with the educational madrasah system referred to by the media today.
} 
eliminated their cohesive unity. In contrast, observe the traditional image of the various branches of the tree of knowledge related to the trunk of the tree. By default, knowledge has become separated from both spirituality and morality. (Nasr, 1993) It is important to understand that compartmentalization should not be confused with the specialization of skills in a particular field. Specialization is a necessity for socio-economic progress within a society but only so long as the bigger picture is in place. In other words, people should not confine themselves to the pieces of the puzzle only, but should be fully aware of and understand the bigger picture as well. This aspect of education is missing in modern educational systems.

The concept of education in the classical sense of training the mind and soul has not completely disappeared, especially in older educational institutions and church sponsored schools, and wherever liberal arts educations flourishes, but it has been critically challenged by the new educational philosophy. Educational systems established by various European states and America focus on the propagation of national ideals and philosophies of new secularism, nationalism, utilitarianism, public welfare and economic goals of material progress, which has nearly become a religion in and of itself. Ideas of evolutionism, progress, doctrinaire socialism, psychoanalysis, etc., have all had their origin in modern educational institutions from where they have infiltrated all other parts of society. Consequently, today, in most modern Western institutions of learning, the truth is discussed in topics of natural and mathematical sciences, but in the humanities and social sciences teachers rarely discuss the truth presenting most subjects in a completely relativistic manner as if the truth did not exist at all. Yet, precisely because the university draws the most perceptive and intelligent members of society to itself and because the university itself predates the rise of modernism, universities continue to serve as a critic of the world even today.

What is important to understand here is that Europe began to separate religious worldviews from their other aspects of life in the post-Galilean era or post-Luther era, but similar reasons did not exist for Muslims. For Muslims, the tendency toward ${ }^{3}$ modernism was acquired from the affects of many generations of colonization. For example, a country colonized by Britain has likely copied British models. Cases in point include Muslim India, Nigeria and Pakistan (Nasr, 1993). Countries colonized by France, such as seen in North Africa, adopted French models and those colonized by the Dutch, such as seen in Indonesia, adopted Dutch models. The impact of secular tendencies within the Muslim world has led to a great crisis resulting from their direct conflict with traditional institutions of learning that base their philosophy upon the unity of knowledge, the servitude of man to God, the centrality of Divine Revelation, and all the other principles which characterize the Islamic worldview. This conflict can be observed in secondary and primary schools in many larger cities of most Islamic countries where western models have been copied in one form or another.

\footnotetext{
${ }^{3}$ Galileo (1564-1642) was an Italian physicist, mathematician, and an astronomer. Martin Luther (1483 1546) was a German theologian, university professor, Father of Protestantism. Galileo and Luther are among those who brought about a revolutionary paradigm shift in the worldview of medieval Europe.
} 


\section{Impact of the Educational Culture on the Socio-Economic Fabric of a Nation}

To have a civil and successful society, citizens should be educated to be responsible, thoughtful and innovative. This intricate and challenging task requires a deep understanding of ethical principles, moral values, political theory, aesthetics, and economics, not to mention an understanding of what children are, in themselves and in society. Progress and economic success in every practical field depends on such an educational culture. (Kneller, 1971) An individual's capacity to develop and fulfill purpose depends most on proper preparation in childhood; the better the foundation, the more successful the individual; the more successful the individual, the more positive the impact on society as a whole.

Academic education has become the norm and standard prerequisite for job placement. Yet, companies and individuals look beyond 'normal' education to what they deem as a good solid educated person/worker. Numerous books have been written on Business and Professional Ethics (Richardson, 2009) and classes are being offered to the current and future business executives especially to make sure that when they make decisions, their decisions are not only pragmatic but ethically, morally, environmentally, individually, socio-economically, and globally sound.

In the early 1900s prominent researchers such as E.L. Thorndike came to recognize that the traditional definition of intelligence restricted to cognitive aspects was not sufficient. He first described the ability to identify the nature of and manage people as social intelligence. (Thorndike, 1920) Much later, Salovey and Mayer called this ability "to monitor one's own and other's feelings and emotions, to discriminate among them and to use this information to guide one's thinking and actions" as emotional intelligence (EI). In other words, El involves the capacity to recognize and manage one's own emotions as well as the emotions of others to maximize interpersonal relations. (Salovey \& Mayer, 1990)

Today's employers are looking for well-educated and successful people who have good communication skills along with a high level of emotional intelligence (EI). Therefore, a successful educational culture must encompass the acquisition of such skills. An employed citizenship can build the nation. Employed citizens are not only consumers who fulfill their needs of shelter, food and education but also provide a source of income for the nation via taxation of income. Clearly, higher rates of education enable countries to achieve optimum levels of economic growth and expansion through the maximized use of modern technologies for development in all areas.

\section{Prevalent Systems of Education}

Education can be divided into informal and formal categories. Informal education includes educational opportunities often subsidized by society, such as museums and libraries. It also consists of any knowledge or skills developed during the course of life or as a result of apprenticeship or experience practicing a profession. Formal education consists of systematic instruction by professional teachers who apply a specific pedagogy or curricula in their lessons. Education also involves specialist instruction in fields of 
trade such as specific training to be a pilot or welder. Educational systems are established to provide education and training, often for children and the youth in society.

In 1952, the first Protocol to the European Convention on Human Rights, Article 2, obliged all signatory parties to guarantee the right to education. At the international level, in 1966, under Article 13 of the United Nations' International Covenant on Economic, Social and Cultural Rights, the same right to education was guaranteed. Globally, around $70 \%$ of primary-age children are enrolled in primary education, and this proportion is rising (UNESCO, 2008). Under the Education for All programs driven by UNESCO, most countries have committed to achieving universal enrollment in primary education by 2015 , and in many countries, it is compulsory for children to receive primary education.

Secondary education has generally been designed to give a common knowledge base to students, preparing them for further training in a specific profession or for higher education opportunities. In most developed countries nearly $50 \%$ of the population chooses to pursue higher education at some time in their lives. Higher education is, therefore, very important to national economies, both as a significant industry in its own right, and clearly, as a source of trained and educated personnel for the rest of the economy.

\section{What Comprises the Optimum Content of a Successful Educational Culture?}

A successful educational culture is aware that the primary purpose of education encompasses the acquisition of knowledge, a continuum of knowing that ranges from very specific data to the highest levels. This continuum consists of a general hierarchy of overlapping levels of knowing. After recognizing the primary purpose, a proper paradigm should be constructed. Within that paradigm students internalize new information, concepts of data, knowledge, wisdom and realization. This approach to education resembles the progressive education philosophy initiated by John Dewey in the early 1900s.According to Dewey, progressive education involves respect for diversity and the development of a "socially engaged intelligence". A successful educational culture should embrace the teaching as well as the learning of knowledge, proper conduct and technical proficiency. In addition to the development of skills, trades or professions, education must elevate the mental, moral and aesthetic aspects of the students. Students should be trained to be more inquisitive and to develop an ability to think 'outside the box'. ${ }^{4}$

Therefore, effective teaching techniques should present a variety of teaching methods which cover all learning modalities so that different students have equal opportunities to learn in a way that is effective for them (Barbe, et al., 1979).

A successful educational culture employs teachers who at all levels are competent to explain the essence of their respective subjects to a new generation of students. The

\footnotetext{
${ }^{4}$ Thinking outside the box philosophically suggests that understanding and retention increases when students must struggle with data. This steps beyond rote memorization of data, encouraging students to see and think beyond what is taught to them in the classroom.
} 
goal is to establish a sound knowledge base on which students will be able to grow as they are exposed to different life experiences allowing them to develop into useful members of society. Teachers should be able to translate information, good judgment, experience and wisdom into relevant knowledge students can understand, retain and exemplify. Studies from the US suggest that the quality of teachers is the single most important factor affecting student performance and those countries which score highly on international tests have multiple policies in place to ensure that the teachers they employ are as effective as possible (Mckinsey and Company).

\section{Utilizing Indigenous and Cultural Awareness to Improve the Educational Culture}

As an educational method within the scope of informal and formal education systems, the inclusion of indigenous ways of knowing, learning, instructing, teaching and training, has been viewed by many critical and postmodern scholars as fundamentally necessary. Indigenous education ensures that students/learners and teachers/instructors (whether indigenous or non-indigenous) are able to benefit from education in a culturally-sensitive manner that draws upon, makes use of, promotes and enhances the awareness of indigenous traditions, perspectives, worldviews and conceptions (Merriam, et al., 2007). The indigenous student benefits from enhanced academic effectiveness, success and learning outcomes while the non-indigenous students and teachers come to develop greater awareness, respect and appreciation for indigenous communities and peoples (Toulouse, 2007). A prime example of how indigenous methods and content can be used to promote the above outcomes is demonstrated within higher education in Canada. Due to certain jurisdictions' focus on enhancing academic success for Aboriginal learners and promoting the values of multiculturalism in society, the inclusion of indigenous methods and content in education is often seen as an important obligation and duty of both governmental and educational authorities.

\section{Achieving Literacy: Is it Enough?}

Literacy needs to be understood as more than simply having acquired the ability to read and write. Ideally, it involves sustaining a particular worldview and honoring traditional values while simultaneously reinterpreting past experience. Being literate is about living values in contemporary times and visioning a future in which an indigenous way of being can continue to thrive. Teachers must look through the lens of cultural sensitivity and focus on theories related to the connection between learning and social contextframed in terms of 'inclusiveness and respect for differing values, beliefs, experiences, perspectives and environments as strongly correlated with the traditional ways and methods inherent in both individual and collective notions of culture.' Learning is not just something that takes place within the individual; rather, learning includes each learner's interactions and the social environments in which they function (Merriam, et al., 2007). 


\section{Education in Developing Countries - Country in Focus: Pakistan}

Although Pakistan has an active Federal Ministry of Education as well as provincial education ministries, it faces unique challenges to the provision of education to the population. In remote agrarian areas, transportation is an issue for many. Parents often prefer their children to work rather than attend school. The long-term investment of education is a luxury they cannot afford. Although, recent studies suggest that when poor families achieve an economic level that allows them to provide for their basic needs, they often do permit their children to attend school. Also, teachers in Pakistan are generally paid less than other professions; consequently, the most qualified teachers tend to choose to work in professions that are more financially rewarding.

In Pakistan, there are many public schools that receive no books, no supplies and no subsidies from the government and still more schools called 'ghost schools' because they 'exist only on paper, to line the pockets of phantom teachers and administrators' (Belt, 2007). Education in Pakistan is divided into five levels: primary (grades one through five), middle (grades six through eight), high (grades nine and ten, leading to the Secondary School Certificate), intermediate (grades eleven and twelve, leading to a Higher Secondary School Certificate), and university programs leading to graduate and advanced degrees. Overall, literacy in Pakistan is 56\% (Ministry of Education). Literacy for men is $63 \%$ while female literacy is at only $36 \%$ (UNICEF). Enrollment is highest at the primary level with $87.3 \%$. At the secondary level, the percentage drops by nearly half to 44 (Ministry of Education) and post-secondary education claims only $4.6 \%$ enrollment (in contrast to developing countries that maintain average $50 \%$ enrollment in higher education) (World Bank).

During the 1970s demand for higher education outpaced the establishment of new public universities. The system could accommodate only 25 percent all applicants. Many wealthy Pakistanis went abroad to pursue university degrees while others engaged private tutors at home or simply entered the job market without a degree. By 1979, a government commission concluded that in view of poor participation rates at all levels of education, the public sector could no longer be the country's sole provider of education. By the mid-1980s, private educational institutions were allowed to operate only on the condition that they comply with government-recognized standards.

Until 1991, there were only two recognized private universities in Pakistan: Aga Khan University established in 1983; and Lahore University of Management Sciences established in 1985. By 1997, however, there were 10 private universities and in 20012002, this number had doubled to 20. In 2003-2004, Pakistan had a total of 53 private degree-granting institutions. Pakistani universities turn out almost 1.2 million skilled graduates annually (Ministry of Education).

\section{Incorporating Madrasah to Improve its Educational Culture}

Since the War on Terror, attention of the world's media has focused on the madrasah system operating in Pakistan. According to a Harvard/World Bank study, enrollment in Pakistani madrasahs is actually relatively low, with less than 1 percent of all students 
enrolled in a school attending madrasahs. There are as much as 100 times as many children in public schools as there are in madrasahs and almost 40 times as many children in private schools as there are in madrasahs. For the average Pakistani household, the choice of going to a madrasah is simply not a statistically significant option (Khwaja, et al., 2005) (Andrabi, et al., 2005).

Examining time trends, madrasah enrollment actually declined in Pakistan from its creation until the 1980s. It increased somewhat during the religion-based resistance to the invasion of Afghanistan by the Soviets in 1979 and the subsequent rise of the Taliban. In the last few years, the data does not suggest any dramatic increase in madrasah enrollment (Bergen and Pandey, 2005) (Khwaja, et al., 2005). However, madrasahs should be integrated into the mainstream educational culture in order to prevent the emergence of a destructive mindset.

\section{Technology and Applications to Distance Learning: An Option for Pakistan?}

Distance education aims to provide instruction to students who are not physically present. Teachers and students communicate at times of their own choosing by the use technologies rather than attending courses in person. Technology is an increasingly influential factor in education. Technology offers powerful learning tools that demand new skills and understandings of students. These learning tools carry great potential to improve the availability of education. (Moore \& Kearsley, 2005)

Information and communication technologies (ICTs) are a 'diverse set of tools and resources used to communicate, create, disseminate, store, and manage information' (Blurton, 2006). These technologies would include computers and the Internet, broadcasting (radio and television), and telephone. Computers and the Internet can improve informal and formal systems of education at all levels (Gold and Maitland, 1999). But for a developing nation like Pakistan, the use of such technologies is limited due to an underdeveloped infrastructure and the attendant high costs of access. Usually, various technologies are used in combination rather than as the sole delivery mechanism.

The ICT technologies, such as radio and television, are far more accessible to rural Pakistanis. Radio and TV have been used for open and distance learning for over forty years and are perhaps the most practical form of ICTs for developing nations. From the FM Channel in India, universities are able to broadcast a wide variety of educational programs in teacher education, rural development, and programs in agriculture for farmers, science education, creative writing, mass communication, traditional courses in liberal arts, science and business administration. Yet, of all the ICTs, print remains the cheapest, most accessible and, therefore, most dominant delivery mechanism in both developed and developing countries (Potashnik and Capper, 1998). To significantly impact a wider proportion of the population of Pakistan, mediums such as radio, TV and print are the most viable options of ICTs. 


\section{Conclusion}

Pakistan needs more than just a highly technical workforce to elevate its socio-economic infrastructure. A Comprehensive educational culture that incorporates ethical and moral values needs to be implemented to produce a highly efficient and technical workforce as well as responsible citizens. Elevating the educational culture for intellectual and socio-economic progress would require a comprehensive review and overhaul of the prevalent educational system that could be done with the implementation of some of the suggestions highlighted in this paper. 


\section{References}

1 Andrabi, T., Das, J., Khwaja, A., and Zajonc, T. (2005) 'Madrassa Maths', The Economist 19 May.

http://ksghome.harvard.edu/ akhwaja/media/madrassa/Economist.pdf

2 Barbe, W. B., Swassing, R. H., \& Milone, M. N. (1979) Teaching through modality strengths: Concepts and practices. Columbus, OH: Zaner-Bloser.

3 Belt, D. (2007) 'Struggle for the Soul of Pakistan', National Geographic, September 2007, p. 59. Bergen, P., and Pandey, S. (2005) 'The Madrassa Myth', New YorkTimes, 14 June.

4 Blurton, C. (2006). New Directions of ICT-Use in Education. Available at: unesco.org: www.unesco.org/education/educprg/lwf/dl/edict.pdf (2007).

5 CNW Newsgroup. (2007) CNW Newsgroup: Improving Access To Higher Education For Rural Students In Southern Ontario. Available at: http://www.newswire.ca: http://www.newswire.ca/en/releases/archive/March2007/06/c7425.html (2008).

6 Gold, L., and Maitland, C. (1999) What's the difference? A review of contemporary research on the effectiveness of distance learning in higher education. Washington, DC: NEA.

7 John Dewey Project on Progressive Education. (2002).

http://www.uvm.edu/ dewey/articles/proged.html

8 Khwaja, A. I., Zajonc, T., Andrabi, T., and Das, J. (2005) Religious School Enrollment in Pakistan: A Look at the Data. Available at: http://ksg.harvard.edu (2008).

9 Kneller, George F. (1971) Introduction to the Philosophy of Education. New York: John Wiley and Sons. pg.20-21.

10 McKinsey and Company. (2007) "How the World's Best-Performing School Systems Come Out on Top".

a) http://mckinsey.com/clientservice/socialsector/resources/pdf/Worlds Schools_Systems_Final.pdf

b) http://www.mckinsey.com/clientservice/socialsector/ourpractices /philanthropy.asp

11 Merriam, S., Caffarella, R., and Baumgartner, L. (2007) Learning in Adulthood: A Comprehensive Guide. San-Francisco: Jossey-Bass. Pg. 180, 218.

12 Ministry of Education (2008) Government of Pakistan-Literacy Level. http://www.moe.gov.pk/faqs.htm?\#q4. 
13 Moore, M. ; Kearsley, G. (2005) Distance Education: A Systems View, Second, Belmont, CA: Wadsworth.

14 Nasr, S. H. (1993) A Young Muslim's Guide to the Modern World. Lahore: Caravan Press. pg 210.

15 Potashnik, M., and Capper, J. (1998) Distance Education:Growth and Diversity (PDF). Available at: http://www.worldbank.org/fandd/english/pdfs/0398/0110398.pdf (2008).

16 Richardson, John. (2009) Business Ethics 09/10. US: McGraw-Hill/Dushkin.

17 Salovey, P. \& Mayer, J. (1990) Imagination, Cognition, and Personality, 9, 185211.

18 Thorndike, R.K. (1920) "Intelligence and Its Uses", Harper's Magazine 140, $227-$ 335 .

19 Toulouse, P. P. (2007) Supporting Aboriginal Student Success: Self-Esteem and Identity, A Living Teachings Approach. Ontario Education Research Symposium.

20 UNESCO (2008) Education For All Monitoring Report 200:, Net Enrollment Rate in primary education. UNESCO.

21 UNICEF (2007) Literacy level - Men/Women.

http://www.unicef.org/infobycountry/pakistan_pakistan_statistics.html

22 World Bank. (2004) Enrollment Levels. (Participation in Education. http://devdata.worldbank.org/wdi2006/contents/cover.htm 